\title{
25 Research Square

\section{Moving towards a competency-based curriculum: Information analysis of patients in geriatric and special care dentistry}

Nareudee Limpuangthip

Chulalongkorn University Faculty Of Dentistry

Orapin Komin (D Orapin.geriatric@gmail.com)

Chulalongkorn University Faculty Of Dentistry https://orcid.org/0000-0001-6831-9382

Teerawut Tatiyapongpaiboon

Thungyai Hospital

Research article

Keywords: oral condition, curriculum, postgraduate, geriatric dentistry, elderly

Posted Date: July 10th, 2020

DOI: https://doi.org/10.21203/rs.3.rs-40860/v1

License: (c) (i) This work is licensed under a Creative Commons Attribution 4.0 International License.

Read Full License 


\section{Abstract}

Background: There is no core competency for geriatric dentistry and special patient care (GSP) in Thailand. Therefore, the present GSP program was initially developed as a knowledge-based curriculum. The objectives of this study were to improve the present GSP program by analysing information of the patients attending the GSP clinic, and the proposed future GSP curriculum is discussed.

Methods: The GSP curriculum used in 2016-2019 was reviewed. Information of the 130 patients attending the GSP clinic, and those who participated a maintenance recall was analysed. The patients were invited to participate a maintenance recall visit to have their general health and oral conditions reassessed.

Results: Only $50 \%$ of the patients attended a maintenance recall to be assessed for their oral and general health. A model of the future curriculum was developed based on the patients' information. The content descriptions and learning methods of the present GSP curriculum need modification. The oral health care for elderly and special care patients requires more extensive collaboration with multiple health professions. The program has to include more learning sites for students to gain more experience and skills, especially in managing dependent and frail elders.

Conclusions: Information analysis of the targeted patients is essential to improve and transform a knowledge-based curriculum for geriatric and special patient care dentistry into a competency-based curriculum. The GSP curriculum are present as a model for other institutions to develop their own curriculum related to the oral health care of geriatric and special care patients. Oral health care in elderly and special care patients should encompass not only oral disease problems, but also behavior and social context.

\section{Background}

Due to health care and socioeconomic improvement, the elderly population is projected to grow worldwide, especially in developing countries [1, 2]. Highly developed countries in Asia, such as Korea, Singapore, and China are shifting towards an aged population. Thailand is also moving in the same direction [3]. Since 2005, Thailand has become an aging society where elderly individuals (aged 60 years and above) account for $10 \%$ of the total population, and will be moving towards a super-aged society in 2050 with a $35 \%$ elderly population [4].

Chronic or non-communicable diseases are a major cause of disability and mortality, especially in the elders. The presence of underlying diseases affects their ability to maintain proper oral hygiene, and also lead to oral diseases [5]. Similar to the elders, a group of adolescents or adults, classified as special care patients, is unable to perform routine dental care due to physical, medical, intellectual, psychological, or social impairment [6]. Thus, delivering oral health care to elderly and special care patients is a concern for dental professionals. 
Due to the complexity of dental treatment and patient management, some dental professionals lack confidence to provide appropriate oral health care to special care and elderly patients [7].Moreover, some elderly patients and family caregivers perceive that there are inadequate geriatric dentistry specialists and services [8].Therefore, the inclusion of geriatrics within dental curricula has been the subject of consideration worldwide [9].To date, postgraduate geriatric dentistry programs have been developed in several countries, such as the United States of America [10],European countries [11],and Japan [12]. Furthermore, special care dentistry education is typically provided by the pediatric department [13].

Despite the rapidly increasing number of elderly people, Thai dental students are not well-prepared to provide oral health care for this age group. In 2005, the Thai Ministry of Public Health launched a national oral health plan for elderly Thai people with an aim to improve their oral health and quality of life [14]. One of the strategies was to motivate all dental schools to develop a geriatric dental curriculum at the undergraduate and postgraduate levels, as well as a short-term training program.

Currently, all 13 dental schools in Thailand offer a lecture course in geriatric dentistry at the undergraduate level. Eight dental schools provide a separate and independent program for postgraduate students in geriatric dentistry, including clinical training and oral health promotion programs [15]. In 2016, the Faculty of Dentistry at Chulalongkorn University established the first Master's program entitled "Geriatric Dentistry and Special Patients Care" (GSP); with a goal to be a learning center of oral health care for geriatric and special care patients in South-East Asia. The GSP program is the only international program in Thailand that collaborates with Chulalongkorn University medical school and a dental school in Japan. The program targets elderly patients with complex medical conditions and younger adults who need special care.

There is currently no core competency for geriatric dentistry and special patient care in Thailand. Therefore, the present GSP program was initially developed as a knowledge-based curriculum by adopting models from several Japanese dental schools. The need for oral health care was estimated based on the Thai national oral health surveys [16], as well as the basic database of a previous study in our dental school [17]. Three years into the program, the present curriculum needed to be reviewed, revised, and modified to meet the changing patients' need and their social context, i.e. their living condition, whom they live with, and who supports them financially. This transformation will lead towards a competency-based curriculum. The purpose of this study was to improve the present academic curriculum of the GSP program by analyzing the information of the patients who attended the GSP clinic. The proposed future GSP program is discussed.

\section{Methods}

Ethical approval for the study was provided by the International Review Board Committee of the Faculty of Dentistry, Chulalongkorn University (HREC-DCU 2018-112). The study was performed in accordance with the 2013 Declaration of Helsinki. Written informed consent was received from the patients or a family member who was their legal guardian. 


\section{Curriculum content}

The curriculum content of the GSP program during 2016 to 2019 was reviewed encompassing title courses and credits, teaching methods, instructors, and content descriptions. A model of the future curriculum was developed.

\section{Patients' information}

Patients attending the GSP clinic were classified into 2 groups: 1 ) elderly patients (aged $\geq 70$ years old) with a medically complex condition or functionally dependent, and 2 ) younger patients (age <70 years old) with a physical or psychological disorder affecting their oral health and dental treatment. During 2016-2019, 130 patients received comprehensive dental treatment at the GSP clinic for at least 6 months. The comprehensive dental treatment consisted of 6 phases: 1) systemic phase (medical consultation), 2) emergency phase (any dental procedures to reduce pain or discomfort, such as tooth extraction or emergency endodontic or periodontal treatment), 3) disease control phase (dental caries control, oral hygiene instruction, and behavior management), 4) preparatory phase (surgical, operative, endodontic, and periodontal treatment), 5) rehabilitation phase (dental prosthesis), and 6) maintenance phase.

Some patients did not enroll into the rehabilitation phase. Enrollment depended on the individual's physical and psychological condition, treatment needs, oral health insurance, and family support. The GSP clinic provided a one-stop service where patients could receive all types of dental treatment. The exceptions were dental treatment under general anesthesia and some surgical treatments, such as bony exostosis removal or implant placement. These cases were treated in the operating room by an oral surgeon.

The patients' information was collected from hospital records: socio-demographic status, oral condition, type of dental treatment, and health conditions. The socio-demographic characteristics recorded consisted of age, sex, working status, main source of living expenses, and residential area.

The patients' oral conditions were clinically examined, including the number of remaining natural teeth (less than 20, at least 20) and posterior occluding pairs (less than 4, at least 4). The types of dental treatment comprised operative (filling, dental caries prevention), periodontal (scaling, root planning), endodontic (root canal treatment, pulp treatment), prosthodontic (fixed and removable dentures), and oral surgery treatment (tooth extraction, implant placement).

The patients' health conditions were categorized into types of diagnosed systemic disease and dependency status. The dependency status of the dental patients in our clinic was classified into 3 levels based on the Chinese-Canadian study of health and aging clinical frailty scale physician version [18]: 1) independent (very fit, well, or well-controlled), 2) semi-dependent (vulnerable, or mildly frail), and 3) dependent (moderately frail, or severely frail). The need for a caregiver in performing daily activities was recorded (need, no need).

\section{Maintenance recall}


The patients were called to invite them for a maintenance recall visit. The patients attending the recall visit had their general health and oral conditions reassessed. Any oral- and denture-related problems reported by the patients were recorded.

\section{Data analyses}

Data analyses were performed using the IBM Statistics Package for the Social Sciences (SPSS) version 22.0. Descriptive statistics was used to assess the characteristics of the patients and those who had a maintenance recall visit, and reported as a percentage (\%).

\section{Results}

\section{Curriculum content}

The two-year GSP program consists of academic, clinical, and research content. Its requirements include attending and passing the following courses: 1) core courses in gerontology and geriatric dentistry and special need patients, and dental research, 2) clinical courses where they perform diagnosis, designing rationale treatment plans, and patient management, and 3) research related to elderly and special care patients. Graduate students receive a Master of Science (M.Sc.) in Geriatric Dentistry and Special Patients Care (International program).

Each year, there were approximately 5 to 10 postgraduate students, already employed by public hospitals $(80 \%)$ or private clinics (20\%). The program was taught by faculty from the medical (25\% physicians) and dental schools (75\% dental specialists). The dental specialists comprised $30 \%$ prosthodontists, $15 \%$ operative dentists, $15 \%$ periodontists, $15 \%$ oral and maxillofacial surgeons, $15 \%$ community dentists, and the rest (10\%) were endodontists, oral medicine dentists, and oral and maxillofacial radiologists. The program received $70 \%$ funding from the government, $10 \%$ from the Faculty, and $20 \%$ from tuition fees.

Table 1 presents the 40-credit courses, teaching methods, and content descriptions in the GSP program. The 2 teaching methods are classroom-based learning (lectures, paper discussion) and clinical training (in the GSP clinic and off-site). In the GSP clinical curriculum, the students provide comprehensive dental treatment for the patients attending the clinic. During a summer course prior to the second year, the students attend a geriatric dentistry short course at the collaborating Japanese dental school for 2 weeks. In the future curriculum, the amount of dental treatment will be reduced and the amount of experience in oral disease prevention and management of systemic diseases, especially with respect to special care patients, will be increased. Lecture courses will be implemented as case-based and problem-based learning, paper discussion, or off-site. Other health care professionals, such as a nurse and a nutritionist, will be invited as the instructors.

Table 1. Description of the present and suggested future curriculum content in the Geriatric and Special Patients Care program. 


\begin{tabular}{lcccc}
\hline :ourses & \multicolumn{2}{c}{ Present curriculum } & \multicolumn{2}{c}{ Suggested future curriculum } \\
\cline { 2 - 4 } ó credit) & Teaching & Content descriptions & Additional & Additional content \\
& method & & teaching & descriptions \\
& (instructors) & & method \\
& & & (instructors) & \\
\hline
\end{tabular}

\begin{tabular}{|c|c|c|c|c|}
\hline \multicolumn{5}{|c|}{ I. Core courses (20\%) } \\
\hline $\begin{array}{l}\text { lical aspect } \\
\text { iatric } \\
\text { try } \\
\text { ।) }\end{array}$ & $\begin{array}{l}\text { Lecture } \\
\text { (physicians) }\end{array}$ & $\begin{array}{l}\text { - Physiology and } \\
\text { pathology of ageing } \\
\text { - Common systemic } \\
\text { diseases in the } \\
\text { elders }\end{array}$ & $\begin{array}{l}\text { Clinical practice } \\
\text { in medical } \\
\text { hospital } \\
\text { (physicians, } \\
\text { nutritionist) }\end{array}$ & $\begin{array}{l}\text { - Genetic disorders, } \\
\text { immunodeficiency diseases } \\
\text { - Diet and nutrition }\end{array}$ \\
\hline $\begin{array}{l}\text { l health and } \\
\text { al health } \\
\text { ।) }\end{array}$ & $\begin{array}{l}\text { Lecture } \\
\text { (dental } \\
\text { surgeon) }\end{array}$ & $\begin{array}{l}\text { - Oral manifestations } \\
\text { of systemic diseases } \\
\text { - Dental and } \\
\text { emergency } \\
\text { management of } \\
\text { patients with medical } \\
\text { complexity in the } \\
\text { dental clinic } \\
\text { - Medication taken by } \\
\text { elderly patients }\end{array}$ & $\begin{array}{l}\text { Clinical practice } \\
\text { in a medical } \\
\text { hospital } \\
\text { (physicians, } \\
\text { dental surgeon, } \\
\text { pharmacist) }\end{array}$ & $\begin{array}{l}\text { - Medication taken by } \\
\text { patients with genetic } \\
\text { disorders } \\
\text { - Clinical training with } \\
\text { geriatric medicine and } \\
\text { pharmacologists }\end{array}$ \\
\hline $\begin{array}{l}1 \text { health } \\
\text { ition and } \\
\text { tion } \\
\text { ) }\end{array}$ & $\begin{array}{l}\text { Lecture, group } \\
\text { discussion } \\
\text { (dental } \\
\text { epidemiologist) }\end{array}$ & $\begin{array}{l}\text { - Thai population } \\
\text { structure, health, } \\
\text { and oral health } \\
\text { policies and } \\
\text { strategies, health } \\
\text { inequalities } \\
\text { - Oral health } \\
\text { prevention and } \\
\text { promotion in the } \\
\text { population } \\
\text { - Oral health } \\
\text { indicators, oral } \\
\text { health literacy and } \\
\text { behavior, and oral } \\
\text { hygiene maintenance }\end{array}$ & $\begin{array}{l}\text { Off-site study } \\
\text { (dental } \\
\text { epidemiologist, } \\
\text { nurse, social } \\
\text { service } \\
\text { agencies) }\end{array}$ & $\begin{array}{l}\text { - Participating } \\
\text { elderly/community club } \\
\text { - Increased oral health } \\
\text { promotion and disease } \\
\text { prevention program } \\
\text { - Improving oral health } \\
\text { literacy for the elders }\end{array}$ \\
\hline
\end{tabular}

\begin{tabular}{lllll}
\hline sthodontic & Lecture & - Basic concepts in & Case-based and & - Personalized treatment \\
lers & (prosthodontist) & removable and fixed & problem-based & plan for the elders \\
1) & & prosthodontics, & learning & - Dental materials of choice \\
& & implant-retained & (prosthodontist) & - Prosthodontic care and \\
& & & maintenance
\end{tabular}


- Prosthetic treatment

for the elders

\begin{tabular}{llll}
\hline eral & Paper & - Basic knowledge in & $\begin{array}{l}\text { Paper } \\
\text { treating and }\end{array}$ \\
ric seminar & $\begin{array}{l}\text { discussion } \\
\text { (operative }\end{array}$ & $\begin{array}{l}\text { preventing dental } \\
\text { case-based }\end{array}$ & $\begin{array}{l}\text { caries and } \\
\text { learning }\end{array}$ \\
dentist, & periodontal disease & \\
endodontist, & periodontist) & - Basic endodontic & \\
& treatment and & \\
& & emergency pulp & \\
& & treatment & \\
& &
\end{tabular}

\begin{tabular}{lllll}
\hline eral & Paper & - Oral & Paper & Oral manifestation in \\
ric seminar & discussion & lesions/manifestations & discussion, & patients with genetic \\
& (oral & in the elders & case-based and & disorders and \\
1) & radiologist, oral & - Radiographic image & problem-based & immunodeficiency diseases \\
& medicine & and interpretation & learning & \\
& dentist) & & &
\end{tabular}

\begin{tabular}{|c|c|c|c|c|}
\hline $\begin{array}{l}\text { anced } \\
\text { ric seminar }\end{array}$ & $\begin{array}{l}\text { Paper } \\
\text { discussion } \\
\text { (operative } \\
\text { dentist, } \\
\text { endodontist, } \\
\text { periodontist, } \\
\text { oral medicine } \\
\text { dentist) }\end{array}$ & $\begin{array}{l}\text { - Advanced operative, } \\
\text { endodontic, and } \\
\text { periodontal } \\
\text { treatment in the } \\
\text { elders } \\
\text { - Management of oral } \\
\text { lesions in the elders }\end{array}$ & $\begin{array}{l}\text { Paper } \\
\text { discussion, } \\
\text { case-based } \\
\text { learning, } \\
\text { problem-based } \\
\text { learning }\end{array}$ & $\begin{array}{l}\text { - Managing dental caries and } \\
\text { oral lesions in elderly and } \\
\text { special care patients } \\
\text { - Advanced dental materials } \\
\text { for dental caries prevention }\end{array}$ \\
\hline $\begin{array}{l}\text { ranced } \\
\text { ric } \\
\text { ar II } \\
\text { ।) }\end{array}$ & $\begin{array}{l}\text { Off-site study in } \\
\text { Japan } \\
\text { (course } \\
\text { director) }\end{array}$ & $\begin{array}{l}\text { - Visiting specialized } \\
\text { clinic in a dental } \\
\text { school in Japan } \\
\text { (dysphagia clinic, } \\
\text { clinic for special } \\
\text { care patients) } \\
\text { - Research discussion } \\
\text { - Observing advanced } \\
\text { technology in } \\
\text { geriatric and special } \\
\text { care dentistry) }\end{array}$ & $\begin{array}{l}\text { Off-site study in } \\
\text { Thailand } \\
\text { (physicians, } \\
\text { oral and } \\
\text { maxillofacial } \\
\text { surgeons, } \\
\text { nurses) }\end{array}$ & $\begin{array}{l}\text { - Visiting a nursing home or } \\
\text { hospital for disabled } \\
\text { patients in Thailand } \\
\text { - Family medicine and } \\
\text { geriatric medicine } \\
\text { - Off-site study in Japan will } \\
\text { be optional. }\end{array}$ \\
\hline $\begin{array}{l}\text { search } \\
\text { dology } \\
\text { ntistry } \\
\end{array}$ & $\begin{array}{l}\text { Lecture and } \\
\text { practice-based }\end{array}$ & $\begin{array}{l}\text { Research methods, } \\
\text { Outlined research } \\
\text { proposal, A mock-up } \\
\text { research proposal }\end{array}$ & - & $\begin{array}{l}\text { Analysis of the article } \\
\text { related to geriatric and } \\
\text { special care dentistry }\end{array}$ \\
\hline ics in & $\begin{array}{l}\text { Lecture and } \\
\text { practice-based }\end{array}$ & $\begin{array}{l}\text { Descriptive and } \\
\text { analytical statistics }\end{array}$ & - & - \\
\hline
\end{tabular}




\begin{tabular}{llll} 
try & \multicolumn{4}{c}{$\begin{array}{l}\text { in dental research, } \\
\text { using SPSS program }\end{array}$} \\
\hline year & II. Clinical courses $(50 \%)$ & \\
1 & - Clinical & - Comprehensive oral & \\
& practice in & health care, rational & - GSP students will be a \\
nd year & dental school & treatment plan & coordinator who is \\
1 & (all dental & - Comprehensive oral & responsible for planning of \\
& specialist) & health care, & comprehensive care, and \\
& - Off-site study & observing physicians & provide only minor \\
& in medical & & treatment or maintenance. \\
& hospital & & - Postgraduate students from \\
& & & other \\
& & & departments provide further \\
& & & required treatment. \\
& & & - Patient management for \\
& & & dental treatment in the
\end{tabular}

\section{Thesis (30 \%)}

year

nd (up to

;h year)

\section{- Proposal}

examination

- Thesis defense:

Research

presentation,

Publication

\section{Patients' information}

From 2016 to 2019, 130 patients attending the GSP clinic. Approximately 57\% were newly-registered patients and $43 \%$ were referred from other departments. Table 2 presents the characteristics of the patients who received comprehensive dental treatment from the GSP students and those attending a maintenance recall. The patients $78.0 \pm 10.7$ years old (mean $\pm S D$ ), ranging from 18 to 95 years. Most patients resided in Bangkok (84.6\%) and received living expenses from their family (69.2\%). Evaluating the patients' oral conditions revealed that $85-90 \%$ had less than 20 remaining teeth and less than 4 posterior occluding pairs. Their dental treatment needs were predominantly dental prostheses, followed by operative and periodontal treatment.

The elderly patients possessed at least one chronic non-communicable disease. Special care conditions in the younger patients (5\%) were neck cancer, hemiplegia by stroke, cerebral palsy, Maffucci syndrome, Down's syndrome, and psychiatric disorders. Approximately $40 \%$ of the patients needed a care giver to assist them in their daily activities.

Table 2. Characteristics of all patients and those who attended a maintenance recall. 


\begin{tabular}{|c|c|c|}
\hline Variables & $\begin{array}{c}\text { All patients } \\
(\mathrm{N}=130) \\
\%\end{array}$ & $\begin{array}{l}\text { Patients receiving a maintenance recall visit }(\mathrm{N}=62) \\
\qquad \%\end{array}$ \\
\hline \multicolumn{3}{|c|}{ Socio-demographic characteristics } \\
\hline Age: $<65$ years & 4.6 & 3.2 \\
\hline $65-74$ & 20.8 & 25.8 \\
\hline $75-84$ & 49.2 & 51.6 \\
\hline$\geq 85$ & 25.4 & 19.4 \\
\hline Sex: Male & 43.1 & 46.8 \\
\hline Female & 56.9 & 53.2 \\
\hline Work status: Not working & 86.2 & 82.3 \\
\hline Currently working & 13.8 & 17.7 \\
\hline \multicolumn{3}{|l|}{ Main source of living expenses: } \\
\hline Themselves (assets, passive income) & 19.2 & 17.7 \\
\hline Family & 69.2 & 71.0 \\
\hline Both & 11.6 & 11.3 \\
\hline Residential area: Bangkok & 84.6 & 82.3 \\
\hline Not Bangkok & 15.4 & 17.7 \\
\hline \multicolumn{3}{|c|}{ Oral conditions } \\
\hline Number of remaining teeth: $<20$ & 85.4 & 88.7 \\
\hline$\geq 20$ & 14.6 & 11.3 \\
\hline Posterior occluding pair: $<4$ & 87.7 & 90.3 \\
\hline$\geq 4$ & 12.3 & 9.7 \\
\hline \multicolumn{3}{|c|}{ Type of dental treatment } \\
\hline Prosthodontic & 93.1 & 96.8 \\
\hline Periodontal & 68.5 & 79.0 \\
\hline Operative & 60.8 & 67.7 \\
\hline Endodontic & 6.9 & 8.1 \\
\hline Oral surgery & 29.2 & 25.5 \\
\hline \multicolumn{3}{|c|}{ Health condition } \\
\hline \multicolumn{3}{|l|}{ Dependency status: } \\
\hline Independent & 66.9 & 69.4 \\
\hline Semi-dependent & 16.9 & 19.4 \\
\hline Dependent & 16.2 & 11.3 \\
\hline \multicolumn{3}{|l|}{ Diagnosed underlying disease: } \\
\hline High BP & 57.7 & 56.5 \\
\hline Diabetes mellitus & 27.7 & 29.0 \\
\hline High cholesterol & 34.6 & 50.0 \\
\hline Cardiovascular diseases & 29.2 & 40.3 \\
\hline Kidney disease & 5.4 & 8.1 \\
\hline Lung disease & 3.8 & 3.2 \\
\hline Osteoporosis & 10.8 & 16.1 \\
\hline Cancer & 3.1 & 4.8 \\
\hline Parkinson's disease & 5.4 & 6.5 \\
\hline Dementia & 11.5 & 11.3 \\
\hline \multicolumn{3}{|l|}{ Care giver: } \\
\hline No need & 54.6 & 59.7 \\
\hline Need & 45.4 & 40.3 \\
\hline
\end{tabular}




\section{Maintenance recall}

Out of 130 patients, 28 patients could not be contacted and 11 had passed away. After a telephone invitation, 29 patients refused to attend a periodic dental check-up due to the following reasons: having more serious physical impairments $(n=18)$, moving to another clinic/hospital because they were dissatisfied with the denture fabricated at the GSP clinic $(n=7)$, and migrating to other provinces $(n=4)$. Among the 62 patients who attended a maintenance recall visit at the GSP clinic, $74.2 \%$ reported emerging problems mainly gingival or oral tissue irritation/inflammation (30.7\%), dental caries or dislodged restoration (29.0\%), and an ill-fitting denture (11.3\%).

\section{Discussion}

Prior to establishing the present GSP program, geriatric dentistry was taught at the postgraduate level by the prosthodontic department, because elderly patients commonly seek dental prosthesis treatment. The content was subsequently simplified and taken as a one-credit lecture by the fifth-year undergraduate students. The GSP program was initially developed as a knowledge-based curriculum. After the program had been in operation for 3 academic years, the present curriculum and patients' information were reanalyzed with an aim to continually improve and transform the curriculum into a competency-based curriculum.

Previously, elderly patients with medical complexity or functional limitation underwent dental treatment at several departments, depending on the patient's symptoms and dental treatment needs. Special care patients were managed at the pediatric department. After the age of 15 , some of these patients were treated at other departments. However, there were some difficulties when referring patients to several clinics where the dentists lacked the required management skill. Currently, the GSP clinic serves as a one stop service center providing dental treatment for elderly and special care patients. The present and future curriculum of the GSP program are shown in Table 1.

Graduate geriatric dentistry education is available in several developed countries, but varies between universities and countries. Most dental schools provide a separate program in geriatric dentistry at the postgraduate level [10-12]. Some dental schools treat independent elderly patients in the prosthodontic clinic and frail elderly in the geriatric clinic $[19,20]$. Special care patient management is a part of the pediatric department or an isolated program $[21,22]$. The objectives of the GSP program focus on both elderly and special care patients to create a holistic oral health care center for patients with physical or psychological complexity, regardless of their age.

Presently, both physicians and dental professionals are responsible for classroom-based learning. Physicians provide lecture courses based on their specialties, but do not participate in a clinical section. Our results indicated that most patients attending the GSP clinic were elderly who had several complex non-communicable diseases consisting of sudden-degenerative (e.g. stroke) and slow-degenerative conditions (e.g. neurodegenerative diseases, dementia, and Alzheimer's disease). The present curriculum 
already provides extensive lectures on systemic diseases of the elders in relation to their dental needs, but does not provide sufficient knowledge and clinical skill to manage special care patients. The current number of younger patients with special care conditions are low, but are expected to increase when the referral system is well-established. The future curriculum has to provide more information on special care conditions, ranging from degenerative diseases to genetic disorders. By collaborating with a medical school, students would have a greater opportunity to engage in various special care centers, allowing them to gain clinical experience in managing patients with various systemic conditions.

Currently, the first-year GSP students mainly observe and provide oral health care for dependent elderly and assist the second-year students. After having lectures and experience off-site, students are allowed to manage more complex cases, such as dependent and frail patients who have severe biological or psychological impairments. Based on our data, most elderly patients who attended the GSP clinic needed removable dentures, followed by periodontal and operative treatment. Currently, the GSP students provide all types of dental treatment, except for complex endodontic treatment, oral surgery, and sedation. However, performing comprehensive treatment may not be possible in the near future when the number of elderly and special care patients increase. The future curriculum will result in the GSP clinic being a one-stop service center that includes students from several departments to reduce fragmented care. Didactic geriatric content needs to be integrated into all relevant clinical departments that deal with elderly patient care. The curriculum will include more case-based and problem-based learning methods to improve decision-making, clinical skill, and problem-solving skills for students. The GSP students will be responsible for assessing, conducting, and organizing dental treatment plans. They will also act as a coordinator in communicating and encouraging family members, caregivers, and the healthcare team to form a holistic care approach.

As an international program, the curriculum includes a short course for visiting and observing the geriatric clinic and advanced technology at the collaborating dental school in Japan. The purpose is to broaden students' experience in geriatric and special care dentistry in the other country. Because the GSP clinic at the dental faculty is independently located from a medical hospital, the GSP students lack clinical experience in managing dependent and frail elders. Dependent elderly and special care patients, registered at a hospital, are generally referred to the hospital dental department when dental treatment is needed. The dental department in the medical hospital provides treatment, but not education; however, it is a good learning site for our GSP students. Therefore, the future curriculum will incorporate more out-ofclass learning and clinical experiences. The teaching sites will be expanded from the dental school to medical institutions, hospitals for disabled people, nursing homes, and community hospitals.

Our data demonstrated that, despite residing in Bangkok, more than half of the patients did not receive regular maintenance care. In accordance with other studies [23,24], a major obstacle in oral health care accessibility is due to the patient's functional limitations and lack of family or care giver support. Some caregivers are unable to evaluate oral condition or provide basic oral health care [25]. Students need to provide additional clinical chair-time to provide a basic oral health care knowledge and skill for patients and their caregivers. Developing a certified caregiver training program is suggested to improve health

Page $11 / 15$ 
attitudes and oral health literacy. In the future, an active approach for oral disease prevention and oral health promotion would be conducted through home visits, mobile dental units, and teledentistry. Using advanced communication technologies, we believe that teledentistry would benefit for elderly individuals who have difficulty in accessing oral health care by providing them dental consultations and oral health care advice [26].

Among the patients receiving maintenance recalls, $75 \%$ had emerging oral health problems. Moreover, many patients had more serious health conditions leading to poorer oral self-care or swallowing difficulty. In addition to oral rehabilitation, the curriculum needs to focus more on the behaviour management of uncooperative patients, oral disease prevention, and other oral care with adjunctive materials and special instruments. Dietary consultation and nutritional assessment should become a part of oral health care.

This study revealed the importance of continually analyzing patients' information to improve the curriculum in geriatric and special patients care dentistry, to meet the changing needs of patients and social context. Oral health care concepts have to extend beyond oral rehabilitation to oral health promotion and prevention. A multidisciplinary team should be established to be responsible for the GSP program. The team should comprise collaborating dentists, physicians, pharmacists, nurses, and rehabilitation nutritionists who work closely with family members and social service agencies. Based on the concept of family medicine, students should learn how to create a personalized treatment plan by considering not only disease problems, but also the behavioural and social context of individuals [27]. The aim of the future GSP program is to produce a dental geriatrician who is an expert in oral health and able to integrate oral into general health.

The present study encourages other institutions to develop their own curriculum related to the oral health care of geriatric and special patients based on their patients' needs and social context. The findings from the GSP program were data from an urban Thai dental school where patient characteristics and their needs could be different from those in rural areas. Further study is recommended to comprehensively review the geriatric curriculum in provincial Thai dental schools in order to develop core competency in geriatric dentistry postgraduate program. For further curriculum improvement, feedback from the present and past students of the program should be collected.

\section{Conclusions}

Information analysis of the targeted patients is the essential to improve and transform a knowledgebased curriculum for geriatric and special patient care dentistry into a competency-based curriculum. Because the dental treatment and management of elderly and special care patients are complex and unique, the program needs to have extensive collaborations with other health professions outside the dental school. The more learning sites, the more opportunities for the students to gain clinical experiences and skill. Oral health care in elderly and special care patients should encompass not only oral disease problems, but also behavior and social context. 


\section{List Of Abbreviations}

GSP, geriatric and special patient care; M.Sc., Master of Science; SD, standard deviation.

\section{Declarations}

\section{Ethics approval and consent to participate}

The study protocol was approved by the International Review Board Committee of the Faculty of Dentistry, Chulalongkorn University (HREC-DCU 2018-112) and was performed in accordance with the 2013 Declaration of Helsinki. Written informed consent was received from the patients or a family member who was their legal guardian.

\section{Consent for publication}

Not applicable

\section{Acknowledgements}

The authors acknowledge the Geriatric and Special Patients Care clinic, Faculty of Dentistry, Chulalongkorn University, for providing a location to collect data. We gratefully acknowledge Dr. Kevin Tompkins for language revision of the manuscript.

\section{Availability of data and material}

The datasets used and/or analysed during the current study are available from the corresponding author on reasonable request.

\section{Competing interests}

The authors declare that there are no competing interests.

\section{Funding}

None

\section{Authors' contribution}

$\mathrm{NL}$ and OK contributed to the study conception and design, data acquisition, analysis, and interpretation, writing and revising of the article, and final approval of the version to be published. TT contributed to the data acquisition, data analysis and interpretation, revising of the article, and final approval of the version to be published.

\section{Authors' information}


Nareudee Limpuangthip is currently working as a lecturer at the department of prosthodontics at Chulalongkorn University, Bangkok, Thailand. She holds a PhD in prosthodontics from Chulalongkorn University. Her research interests are in the field of prosthodontics and geriatric dentistry, and how to improve the oral health and quality of life of elderly people.

Orapin Komin is currently working as a lecturer at department of prosthodontics at Chulalongkorn University, Thailand. She holds a PhD in prosthodontics from Tokyo Medical and Dental University in Japan. She is also the founder and director of the Geriatric Dentistry and Special Patients Care program of the dental school. Her research interests are in the field of geriatric dentistry and prosthodontics.

Teerawut Tatiyapongpaiboon is currently working as a dentist at Thungyai Hospital, Nakhon Si Thammarat, Thailand. He holds a Master Degree in Geriatric Dentistry and Special Patients Care (International Program) from Chulalongkorn University.

\section{References}

1. Broadbent JM, Zeng J, Foster Page LA, Baker SR, Ramrakha S, Thomson WM. Oral health-related beliefs, behaviors, and outcomes through the life course. J Dent Res. 2016;95(7):808-13.

2. Shrestha LB. Population aging in developing countries. Health Affairs. 2000;19(3):204-12.

3. World Population Prospects - Population Division. United Nations. 2019. Accessed June 2020.

4. Report on the 2014 survey of the older persons in Thailand. National Statistical Office. 2008.

5. Petersen PE, Yamamoto T. Improving the oral health of older people: the approach of the WHO global oral health programme. Community Dent Oral Epidemiol. 2005;33(2):81-92.

6. Definition of special health care needs. Pediatr Dent. 2016;38(6):16.

7. Ferguson FS, Berentsen B, Richardson PS. Dentists' willingness to provide care for patients with developmental disabilities. Spec Care Dentist. 1991;11(6):234-7.

8. Paley GA, Slack-Smith L, O'Grady M. Oral health care issues in aged care facilities in Western Australia: resident and family caregiver views. Gerodontology. 2009;26(2):97-104.

9. Slack-Smith LM, Hearn L, Wilson DF, Wright F. Geriatric dentistry, teaching and future directions. Aust Dent J. 2015;60 Suppl 1:125-30.

10. Ettinger RL, Goettsche ZS, Qian F. Postdoctoral teaching of geriatric dentistry in U.S. dental schools. J Dent Educ. 2017;81(10):1220-6.

11. Kossioni A, McKenna G, Muller F, Schimmel M, Vanobbergen J. Higher education in gerodontology in European universities. BMC Oral Health. 2017;17(1):71.

12. Kitagawa N, Sato $\mathrm{Y}$, Komabayashi T. Graduate and undergraduate geriatric dentistry education in a selected dental school in Japan. Eur J Dent Educ. 2011;15(4):231-5.

13. Sherman CM, Anderson RD. Special needs education in Canadian dental school curriculum: is there enough? J Can Dent Assoc. 2010;76:a11.

14. The 2nd national oral health plan for the Thai elders 2005-2022. Bureau of Dental Health. 2005. 
15. The 2nd meeting of the collaboration for better oral health of older Thai people. Bureau of Dental Health. 2020.

16. The 7th national oral health report 2011. Report No. 2018-09-11. Bureau of Dental Health. 2011.

17. Youdying W. The characteristics of elderly patients seeking care at faculty of dentistry, chulalongkorn university during 2007-2009 and the development of dental service electronic database for the aged. Bangkok: Chulalongkorn University, 2011. MS thesis.

18. Rockwood K, Song X, MacKnight C, Bergman H, Hogan DB, McDowell I, et al. A global clinical measure of fitness and frailty in elderly people. Can Med Assoc J. 2005;173(5):489-95.

19. Hiroshima University. Special Care Dentistry. https://www.hiroshimau.ac.jp/en/dent/research/lab/hospital/Special_Care_Dentistry. Accessed 31 June 2020.

20. Tokyo Medical and Dental University. Graduate School of Medical and Dental Sciences (Dentistry). http://www.tmd.ac.jp/english/dept/dentistry/index.html. Accessed 31 June 2020.

21. Monteserin-Matesanz M, Esparza-Gomez GC, Garcia-Chias B, Gasco-Garcia C, Cerero-Lapiedra R. Descriptive study of the patients treated at the clinic "integrated dentistry for patients with special needs" at Complutense University of Madrid (2003-2012). Med Oral Patol Oral Cir Bucal. 2015;20(2):e211-7.

22. Polli VA, Sordi MB, Lisboa ML. Dental management of special needs patients: A literature review. Global Journal of Oral Science. 2016;2:33-45.

23. Limpuangthip N, Purnaveja S, Somkotra T. Predisposing and enabling factors associated with public denture service utilization among older Thai people: a cross-sectional population-based study. BMC Oral Health. 2019;19(1):220.

24. Montini T, Tseng TY, Patel H, Shelley D. Barriers to dental services for older adults. Am J Health Behav. 2014;38(5):781-8.

25. Komin O, Weerapol P. Oral Health Status of Patients with Dementia and their Caregivers' Ability in Oral Health and Dysphagia Assessment: A Pilot Study. J Dent Assoc Thai. 2020;70(1):1-10.

26. Jampani ND, Nutalapati R, Dontula BS, Boyapati R. Applications of teledentistry: A literature review and update. J Int Soc Prev Community Dent. 2011;1(2):37-44.

27. Murtagh JE. Paradigms of family medicine: bridging traditions with new concepts; meeting the challenge of being the good doctor from 2011. Asia Pac Fam Med. 2011;10:9. 